\title{
LONG-TERM RESULTS AND COMPLICATIONS AFTER TRABECULECTOMY WITH A SINGLE PER-OPERATIVE APPLICATION OF 5-FLUOROURACIL
}

\author{
R. W. D. BELL, N. E. HABIB and C. O'BRIEN \\ Edinburgh
}

\begin{abstract}
SUMMARY
We retrospectively evaluated a consecutive series of 45 patients (45 eyes) who underwent trabeculectomy augmented with a single intra-operative 5 minute application of 5-fluorouracil (5-FU; $25 \mathrm{mg} / \mathrm{ml})$. All patients were at an increased risk of subconjunctival fibrosis and surgical failure. The mean follow-up period was 24 months (range 12-42, SD 6.9). The mean preoperative intraocular pressure (IOP) was $29.1 \mathrm{mmHg}$ (SD 6.1) and the mean IOP at the last post-operative visit was $16.6 \mathrm{mmHg}(\mathrm{SD} \mathrm{6.4})(p<0.0001)$ with a mean IOP reduction of $42 \%$. The number of medications reduced from a mean of 2.3 (SD 0.7$)$ pre-operatively, to 0.8 (SD 0.7) post-operatively $(p<0.0001)$ and 22 eyes $\mathbf{( 4 9 \% )}$ required no topical treatment for IOP control. An IOP of $21 \mathrm{mmHg}$ or less with or without medications was achieved in $80 \%$ of cases. There was no significant difference in final IOP or success rate over time between low- and high-risk patients, although the low-risk patients did better in the first 12-18 months. Complications included hypotony maculopathy in 2 cases $(4 \%)$, leaking bleb in 5 cases $(11 \%)$ and giant bleb in 1 case $(2 \%)$, giving a total of 8 cases $(18 \%)$ with bleb-related sequelae. In the short to medium term, a single per-operative application of 5-FU is a useful adjunctive treatment during glaucoma filtering surgery for low- to moderate-risk cases, although a steady increase in the failure rate was associated with increasing length of follow-up.
\end{abstract}

The most common cause of failure of glaucoma filtering surgery is the formation of excessive scar tissue beneath the conjunctiva, which occurs as a natural healing response to surgical trauma. ${ }^{1}$ This response is exaggerated in cases of previous ocular

From: Princess Alexandra Eye Pavilion, Royal Infirmary of Edinburgh, Edinburgh, UK

Correspondence to: Dr R. W. D. Bell, FRCOphth surgery, aphakia or uveitis, and also where the patient is of a young age or of African or Asian race. Locally derived fibroblasts are thought to be the principal cellular component responsible for this reaction, ${ }^{1}$ and laboratory studies have shown that proliferation of these cells can be modified via the use of chemotherapeutic agents such as 5-fluorouracil (5-FU) and mitomycin C (MMC). ${ }^{2-4}$

Fluorouracil, a pyrimidine analogue, is an antineoplastic agent which interferes with normal cell mitosis by competitively inhibiting the enzyme thymidilate synthetase and therefore the synthesis of DNA and RNA. 5-FU, when given by subconjunctival injection in the post-operative period, has been shown to increase the success rate of glaucoma filtering surgery in high-risk patients. ${ }^{6-9}$ Likewise, success rates are improved following the use of MMC applied intraoperatively. ${ }^{10-14}$ However, MMC has a more profound inhibitory effect on subconjunctival fibroblasts than 5-FU ${ }^{15}$ and such filtering blebs tend to be extremely thin and avascular with the attendant risks of hypotony maculopathy ${ }^{10,16}$ and bleb-related endophthalmitis. ${ }^{17}$

Administered post-operatively, 5-FU has several disadvantages, not least the need for repeated subconjunctival injections, which can be painful and inconvenient to the patient, and also an associated higher risk of corneal complications. ${ }^{18}$ More recently there has been a trend towards using 5-FU as a single exposure given at the time of surgery, largely based on the results of laboratory studies which suggested that a single intraoperative application would be as effective as repeated subconjunctival injections in inhibiting fibroblast proliferation., ${ }^{2,3}$ Recent clinical studies with limited follow-up (range 3-12 months) supported these findings, with success rates between $83 \%$ and $91 \% .{ }^{19-21}$ Mora et al..$^{22}$ in a large study of 140 eyes with a mean follow-up of 16 months have 
also shown an impressive success rate $(<21 \mathrm{mmHg}$, allowing medications) of $92 \%$, with $72 \%$ having an IOP $<15 \mathrm{mmHg}$ (and $>30 \%$ drop in IOP) at the last follow-up. However, in this study $56 \%$ of eyes had no increased risk of subconjunctival fibrosis. This retrospective study was undertaken to evaluate the longterm efficacy and complications of intraoperative sponge 5-FU application in a group largely consisting of high-risk patients.

\section{PATIENTS AND METHODS}

A consecutive series of 45 eyes in 45 patients undergoing glaucoma filtration surgery with adjunctive 5-FU was studied. There were $25 \mathrm{men}$ and 20 women, all of whom were Caucasian apart from 4 women and 1 man of Asian origin. The mean age was 53.0 years (range 19-78, SD 15.8) and the mean follow-up period was 24 months (range 12-42, SD 6.9). Pre- and post-operative examination included visual acuity, IOP measurement by Goldmann applanation tonometry, slit lamp biomicroscopy and optic disc assessment using a +90 dioptre or +78 dioptre Volk lens. The pre-operative IOP was taken as the mean value of the last three recordings prior to surgery; the post-operative IOP was the value at the last follow-up visit. Visual field perimetry was performed at approximately yearly intervals post-operatively, using threshold (Humphrey, 24-2 program) and supra-threshold (Medmont, Goldmann and Friedmann) analysers.

Surgery was performed on the basis of an uncontrolled IOP despite maximally tolerated medical therapy. Two eyes with a pre-operative IOP of $21 \mathrm{mmHg}$ and $19 \mathrm{mmHg}$ were showing progressive optic nerve damage. There was a total of 5 surgeons ( 3 consultants and 2 senior registrars) who used a standardised surgical technique which included a limbal-based conjunctival flap with or without excision of Tenon's capsule. A small surgical sponge (Sugi Steril, John Weiss) was trimmed and soaked in 5-FU $25 \mathrm{mg} / \mathrm{ml}$ (David Bull Laboratories, Warwick, UK) and then applied to the sclera which was covered with conjunctiva, taking care to try to avoid contact between the cut conjunctival edge and the sponge. The sponge was left in place for 5 minutes and was replenished with 1 or 2 drops of 5-FU every minute using an insulin syringe and a 25 gauge needle. Following this the sclera was thoroughly irrigated with $20 \mathrm{ml}$ normal saline. A one-third to one-half thickness rectangular scleral flap measuring $4 \mathrm{~mm} \times 3 \mathrm{~mm}$ was then dissected into clear cornea and a block of corneoscleral tissue measuring $3 \mathrm{~mm} \times 1 \mathrm{~mm}$ was excised followed by a peripheral iridectomy. The scleral flap was sutured with two 10/0 monofilament nylon sutures and the conjunctiva was closed with interrupted 10/0 monofilament nylon or continuous $8 / 0$ vicryl sutures.
Post-operative medications included topical dexamethasone $0.1 \%$ applied 6-8 times daily and chloramphenicol eye drops 4 times a day. Topical steroids were tailed off slowly over a period of 3 months. Post-operative examinations and measurements were made at 1 day, 1 week, 1 month, 3 months, 6 months and then 6 monthly, or between these times if the clinical situation demanded. Laser suture lysis was performed within the first 2 weeks depending on the IOP and the appearance of the bleb. ${ }^{23}$ Additional subconjunctival 5-FU injections ( $2.5 \mathrm{mg}$ via a 30 -gauge needle into the bleb) were given if there were signs of bleb failure within the first 21 post-operative days. The criteria for surgical outcome were defined as follows:

Complete surgical success: an IOP of $21 \mathrm{mmHg}$ or less without any anti-glaucoma medication.

Qualified success: an IOP of $21 \mathrm{mmHg}$ or less with anti-glaucoma treatment.

Unqualified success: an IOP of $21 \mathrm{mmHg}$ or less regardless of anti-glaucoma treatment.

IOP of less than $15 \mathrm{mmHg}$ and $>30 \%$ drop in IOP: $:^{22}$ regardless of anti-glaucoma treatment.

Failure: an IOP of $21 \mathrm{mmHg}$ or greater regardless of anti-glaucoma treatment.

For the analysis of results the patients were separated into high-risk and low-risk groups. Highrisk factors included previous failed filtration surgery, uveitis, pseudophakia or aphakia or neovascularisation. ${ }^{18,24-26}$ Low-risk factors included age under 45 years, African or Asian race or previous topical medications for over 3 years. ${ }^{27-31}$

A Wilcoxon matched-pairs signed-rank test was used to evaluate the intra-individual changes in IOP and the pre-operative to post-operative change in anti-glaucoma medications. A Kaplan-Meier analysis was performed to assess how success changed over 6 monthly intervals using three criteria: complete success, unqualified success and IOP $<15 \mathrm{mmHg}$. A comparison of the survival curves between the low- and high-risk groups for the three success criteria was undertaken using the log rank test. In addition any pre-operative to post-operative change in optic disc cupping and visual field loss was documented.

\section{RESULTS}

Patient details, including causes of glaucoma and risk factors for surgical failure, are summarised in Table I. Thirty-five patients were at high risk of subconjunctival fibrosis and therefore surgical failure, with many patients having more than one risk factor. There were 10 cases which were in the lowrisk category.

Fig. 1 shows a scatter plot of the pre- and postoperative IOPs. The mean pre-operative IOP was 


\begin{tabular}{|c|c|c|c|c|c|c|c|c|c|c|c|c|c|}
\hline \multirow{2}{*}{$\begin{array}{l}\text { Patient } \\
\text { no. }\end{array}$} & \multirow{2}{*}{$\begin{array}{l}\text { Age } \\
\text { (years) }\end{array}$} & \multirow[b]{2}{*}{ Sex } & \multirow[b]{2}{*}{ Eye } & \multirow{2}{*}{$\begin{array}{c}\text { Follow-up } \\
\text { (months) }\end{array}$} & \multicolumn{2}{|c|}{ IOP $(\mathrm{mmHg})$} & \multicolumn{2}{|c|}{ Medications } & \multicolumn{2}{|c|}{ Visual acuity } & \multirow[b]{2}{*}{ Diagnosis } & \multirow[b]{2}{*}{ Risk factors } & \multirow[b]{2}{*}{ Outcome } \\
\hline & & & & & Pre-op. & Final & Pre-op. & At last visit & Pre-op. & Last & & & \\
\hline 1 & 59 & $\mathrm{~F}$ & $\mathrm{~L}$ & 42 & 36 & 22 & 3 & 1 & $6 / 9$ & $6 / 6$ & POAG & Race & Failure \\
\hline 2 & 54 & $\mathrm{~F}$ & $\mathbf{R}$ & 39 & 28 & 24 & 2 & 1 & $6 / 5$ & $6 / 5$ & POAG & Race & Failure \\
\hline 3 & 42 & M & $\mathbf{R}$ & 33 & 48 & 10 & 3 & 1 & $6 / 60$ & $6 / 60$ & Uveitic glaucoma & Young age, uveitis, pseudophakic, failed trab. & Qualified success \\
\hline 4 & 44 & M & $\mathrm{L}$ & 32 & 42 & 16 & 2 & 3 & $6 / 60$ & $6 / 36$ & Uveitic glaucoma & Young age, uveitis, pseudophakic, failed trab. & Qualified success \\
\hline 5 & 38 & $\mathrm{M}$ & $\mathrm{L}$ & 32 & 26 & 16 & 2 & 0 & $6 / 12$ & $6 / 12$ & POAG & Young age & Complete success \\
\hline 6 & 36 & $\mathrm{~F}$ & $\mathrm{~L}$ & 30 & 23 & 17 & 2 & 1 & $\mathrm{CF}$ & $\mathrm{CF}$ & Secondary glaucoma & $\begin{array}{l}\text { Young age, } \mathrm{PK} \times 2 \text { (Acanthamoeba), pseudophakic, } \\
\text { failed trab. + Molteno }\end{array}$ & Qualified success \\
\hline 7 & 19 & M & $\mathrm{R}$ & 31 & 33 & 30 & 3 & 3 & $6 / 12$ & $6 / 60$ & Uveitic glaucoma & Young age, uveitis, pseudophakic, failed trab. & Failure \\
\hline 8 & 63 & $\mathrm{~F}$ & $\mathrm{R}$ & 28 & 32 & 16 & 1 & 1 & $6 / 24$ & $6 / 12$ & CACG & Failed iridocleisis & Qualified success \\
\hline 9 & 72 & M & $\mathbf{R}$ & 33 & 23 & 7 & 1 & 0 & $6 / 9$ & $6 / 9$ & POAG & Failed trab. & Complete success \\
\hline 10 & 72 & M & $\mathbf{R}$ & 30 & 27 & 15 & 2 & 0 & $6 / 9$ & $6 / 18$ & POAG & Failed trab., previous ALT & Complete success \\
\hline 11 & 65 & M & $\mathrm{L}$ & 30 & 37 & 12 & 2 & 1 & $6 / 36$ & $6 / 60$ & Rubeotic glaucoma & Rubeosis & Qualified success \\
\hline 12 & 36 & $\mathrm{M}$ & $\mathbf{R}$ & 33 & 26 & 24 & 3 & 2 & $6 / 5$ & $6 / 6$ & Pigmentary glaucoma & Young age & Failure \\
\hline 13 & 40 & $\mathrm{M}$ & $\mathrm{L}$ & 27 & 39 & 16 & 2 & 1 & $6 / 60$ & $6 / 60$ & Uveitic glaucoma & Young age, uveitis, pseudophakia & Qualified success \\
\hline 14 & 65 & $\mathrm{~F}$ & $\mathrm{~L}$ & 30 & 28 & 16 & 2 & 2 & $6 / 9$ & $\mathrm{CF}$ & POAG & Race, pseudophakia & Qualified success \\
\hline 15 & 39 & M & $\mathrm{R}$ & 26 & 28 & 12 & 2 & 0 & $6 / 12$ & $6 / 12$ & POAG & Young age & Complete success \\
\hline 16 & 32 & M & $\mathrm{L}$ & 30 & 23 & 10 & 3 & 1 & $6 / 6$ & $6 / 6$ & Uveitic glaucoma & Young age, uveitis & Qualified success \\
\hline 17 & 52 & $\mathrm{~F}$ & $\mathrm{~L}$ & 23 & 19 & 17 & 3 & 1 & $6 / 6$ & $6 / 5$ & POAG & Failed trab. $\times 3$, failed Molteno & Qualified success \\
\hline 18 & 28 & $\mathrm{~F}$ & $\mathrm{R}$ & 26 & 35 & 37 & 2 & 3 & $6 / 9$ & $6 / 12$ & Uveitic glaucoma & Young age, uveitis, aphakic & Failure \\
\hline 19 & 19 & $\mathrm{M}$ & $\mathrm{R}$ & 24 & 34 & 30 & 3 & 3 & $2 / 60$ & $2 / 60$ & Aphakic glaucoma & Young age, aphakic, failed trab. $\times 3$, failed Molteno & Failure \\
\hline 20 & 71 & $\mathrm{~F}$ & $\mathrm{~L}$ & 24 & 26 & 12 & 3 & 1 & $6 / 24$ & $6 / 24$ & POAG & Failed trab. $\times 2$, previous ALT & Qualified success \\
\hline 21 & 52 & $\mathrm{~F}$ & $\mathrm{R}$ & 20 & 21 & 18 & 2 & 0 & $6 / 36$ & $6 / 36$ & POAG & Failed trab. & Complete success \\
\hline 22 & 43 & $\mathrm{~F}$ & $\mathrm{~L}$ & 21 & 26 & 18 & 2 & 0 & $6 / 36$ & $6 / 60$ & Uveitic glaucoma & Young age, uveitis & Complete success \\
\hline 23 & 78 & $\mathrm{~F}$ & $\mathbf{R}$ & 24 & 25 & 27 & 3 & 2 & $6 / 60$ & $1 / 60$ & POAG & Failed trab. & Failure \\
\hline 24 & 52 & $\mathrm{~F}$ & $\mathrm{~L}$ & 20 & 32 & 17 & 3 & 0 & $6 / 9$ & $6 / 9$ & CACG & Pseudophakia, failed trab. & Complete success \\
\hline 25 & 66 & $\mathrm{M}$ & $\mathbf{R}$ & 19 & 24 & 14 & 2 & 0 & $6 / 6$ & $6 / 9$ & POAG & Pseudophakia & Complete success \\
\hline 26 & 63 & $\mathrm{~F}$ & $\mathrm{R}$ & 18 & 29 & 14 & 3 & 0 & $6 / 18$ & $6 / 18$ & POAG & Race & Complete success \\
\hline 27 & 44 & $\mathrm{M}$ & $\mathrm{L}$ & 20 & 26 & 10 & 1 & 0 & $6 / 24$ & $6 / 24$ & Pigmentary glaucoma & Young age & Complete success \\
\hline 28 & 39 & $\mathrm{~F}$ & $\mathrm{~L}$ & 20 & 30 & 23 & 3 & 3 & $\mathrm{CF}$ & $\mathrm{HM}$ & Aniridia & Aniridia, pseudophakia, $\mathrm{PK} \times 3$ & Failure \\
\hline 29 & 36 & $\mathrm{M}$ & $\mathrm{R}$ & 24 & 27 & 28 & 3 & 1 & $1 / 60$ & PL & Aphakic glaucoma & Young age, failed trab. $\times 3$, aphakic & Failure \\
\hline 30 & 61 & $\mathrm{~F}$ & $\mathrm{R}$ & 18 & 32 & 10 & 2 & 0 & $6 / 5$ & $6 / 9$ & CACG & Previous PI, failed trab. & Complete success \\
\hline 31 & 48 & M & $\mathbf{R}$ & 20 & 25 & 17 & 2 & 0 & $6 / 5$ & $6 / 5$ & Pigmentary glaucoma & Race & Complete success \\
\hline 32 & 67 & $\mathrm{M}$ & $\mathbf{R}$ & 19 & 29 & 16 & 2 & 0 & $6 / 6$ & $6 / 9$ & POAG & Failed trab., pseudophakic, previous ALT & Complete success \\
\hline 33 & 65 & $\mathrm{~F}$ & $\mathrm{~L}$ & 18 & 23 & 14 & 2 & 0 & $6 / 12$ & $6 / 12$ & POAG & Failed trab., previous ALT & Complete success \\
\hline 34 & 34 & M & $\mathrm{L}$ & 18 & 32 & 16 & 2 & 0 & $3 / 36$ & $3 / 36$ & ICE syndrome & ICE, young age & Complete success \\
\hline 35 & 72 & $\mathrm{M}$ & $\mathrm{L}$ & 14 & 28 & 15 & 2 & 2 & $1 / 60$ & $1 / 60$ & POAG & Proliferative diabetic retinopathy & Qualified success \\
\hline 36 & 72 & M & $\mathbf{R}$ & 26 & 32 & 8 & 3 & 0 & $6 / 9$ & $6 / 9$ & POAG & Failed trab. & Complete success \\
\hline 37 & 44 & M & $\mathbf{R}$ & 18 & 23 & 12 & 1 & 0 & $6 / 6$ & $6 / 4$ & Pigmentary glaucoma & Young age & Complete success \\
\hline 38 & 50 & $\mathbf{M}$ & $\mathrm{L}$ & 19 & 26 & 14 & 3 & 0 & $6 / 18$ & $6 / 9$ & Uveitic glaucoma & Uveitis, failed trab. $\times 2$ & Complete success \\
\hline 39 & 53 & $\mathbf{M}$ & $\mathbf{R}$ & 19 & 41 & 15 & 3 & 1 & $6 / 12$ & $6 / 9$ & Uveitic glaucoma & Uveitis, failed trab. $\times 2$, pseudophakia & Qualified success \\
\hline 40 & 67 & $\mathrm{~F}$ & $\mathrm{~L}$ & 12 & 26 & 9 & 2 & 0 & $6 / 9$ & $6 / 12$ & POAG & Failed trab. & Complete success \\
\hline 41 & 74 & M & $\mathrm{L}$ & 14 & 34 & 18 & 3 & 1 & $6 / 24$ & $6 / 9$ & Uveitic glaucoma & Uveitis, failed trab. & Qualified success \\
\hline 42 & 78 & $\mathrm{~F}$ & $\mathrm{R}$ & 18 & 31 & 13 & 1 & 1 & $6 / 9$ & $6 / 6$ & POAG & Failed trab. $\times 3$, pseudophakia & Qualified success \\
\hline 43 & 48 & $\mathrm{~F}$ & $\mathrm{~L}$ & 26 & 20 & 10 & 3 & 0 & $6 / 24$ & 6/36 & POAG & Failed trab. $\times 3$ & Complete success \\
\hline 44 & 70 & M & $\mathrm{L}$ & 12 & 31 & 15 & 2 & 0 & $6 / 60$ & $6 / 60$ & CACG & Failed trab., pseudophakia & Complete success \\
\hline 45 & 63 & $\mathrm{~F}$ & $\mathrm{~L}$ & 20 & 25 & 16 & 3 & 0 & $6 / 6$ & $6 / 6$ & POAG & Drops for 10 years & Complete success \\
\hline
\end{tabular}




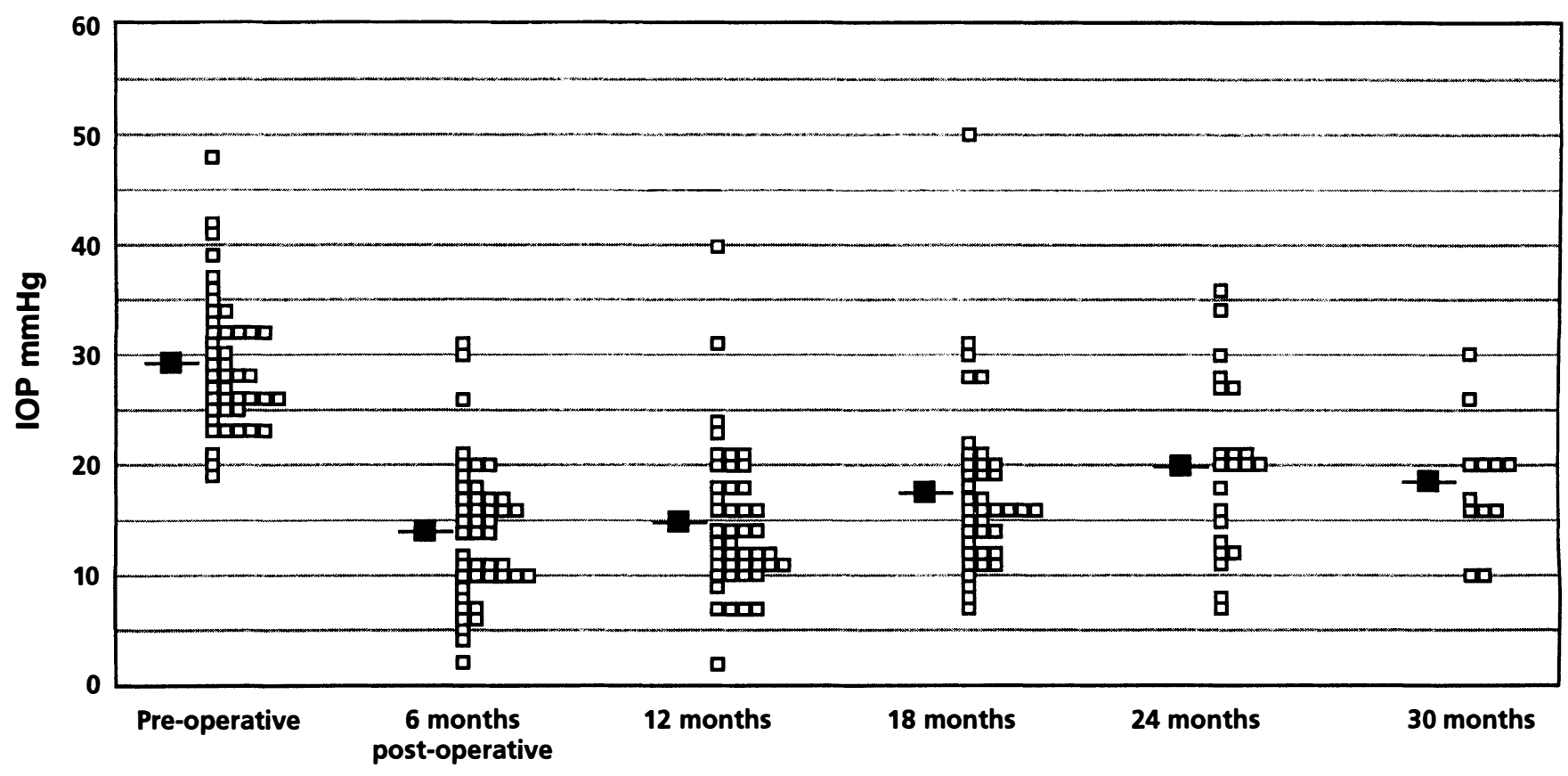

\section{Time}

Fig. 1. Scatterplot of intraocular pressures (IOPs) pre-and post-operatively. The filled squares indicate the mean IOP values.

$29.1 \mathrm{mmHg}$ (range 19-48, SD 6.1) and the mean post-operative IOP at the last follow-up was $16.6 \mathrm{mmHg}$ (range 7-37, SD 6.4) $(p<0.0001)$. Complete success was achieved in 22 eyes $(49 \%)$ and qualified success in 14 eyes (31\%), giving an unqualified success rate of $80 \%$. Nine eyes $(20 \%)$ have failed, 6 of which were in the high-risk group and 3 in the low-risk group (Table I). One of these underwent a further 5-FU trabeculectomy at the time of last follow-up. The mean number of medications pre-operatively was 2.3 (SD 0.7 ) reducing to 0.8 (SD 0.7) post-operatively $(p<0.0001)$. Twenty-three patients $(51 \%)$ required topical treatment at the last follow-up, 20 of whom were in the high-risk group and 3 in the low-risk group. Table II illustrates the IOP reduction for the different risk groups and the group as a whole, and also the success rates for the three different criteria at the time of last followup.

The Kaplan-Meier survival curve for trabeculectomy with per-operative sponge 5-FU is shown in Fig. 2. Survival varies according to the criteria used to

Table II. Intraocular pressure, intraocular pressure reduction and success rates within groups at the final follow-up

\begin{tabular}{lccc}
\hline & $\begin{array}{c}\text { High risk } \\
(n=35)\end{array}$ & $\begin{array}{c}\text { Low risk } \\
(n=10)\end{array}$ & $\begin{array}{c}\text { Total } \\
(n=45)\end{array}$ \\
\hline IOP (mean \pm SD) & $16.5 \pm 6.7$ & $16.7 \pm 5.1$ & $16.6 \pm 6.4$ \\
$\begin{array}{l}\text { IOP reduction (\%) } \\
\text { (mean } \pm \text { SD) }\end{array}$ & $42.5 \pm 23.4$ & $38.8 \pm 17.4$ & $41.7 \pm 22.1$ \\
$\begin{array}{l}\text { Complete success (\%) } \\
\text { Unqualified success (\%) }\end{array}$ & $43(n=15)$ & $70(n=7)$ & $49(n=22)$ \\
$\begin{array}{l}\text { IOP }<15 \text { and >30\% } \\
\text { reduction (\%) }\end{array}$ & $49(n=17)$ & $70(n=7)$ & $80(n=36)$ \\
& & & $47(n=21)$ \\
IOP, intraocular pressure $(\mathrm{mmHg})$. & & \\
\hline
\end{tabular}

define success. Fig. 3 compares the survival curves between low-risk and high-risk eyes for the three different success criteria. There was no significant difference in the survival curves between the two groups (complete success, log rank 1.38; unqualified success, $\log$ rank 0.24 ; IOP $<15 \mathrm{mmHg}$ and $>30 \%$ reduction in IOP, log rank 0.09; significance $\geqslant 2.0$ ).

Argon laser suture lysis was performed to augment bleb formation in the early post-operative period in 4 eyes. Six eyes in the high-risk group showing evidence of early bleb failure required post-operative subconjunctival injections of 5-FU. The number of injections ranged between two and five. Of those eyes that required post-operative subconjunctival 5-FU, 1 eye failed at 4 months, 2 eyes failed at 18 months and the remaining 2 eyes remain controlled on a topical $\beta$-blocker alone.

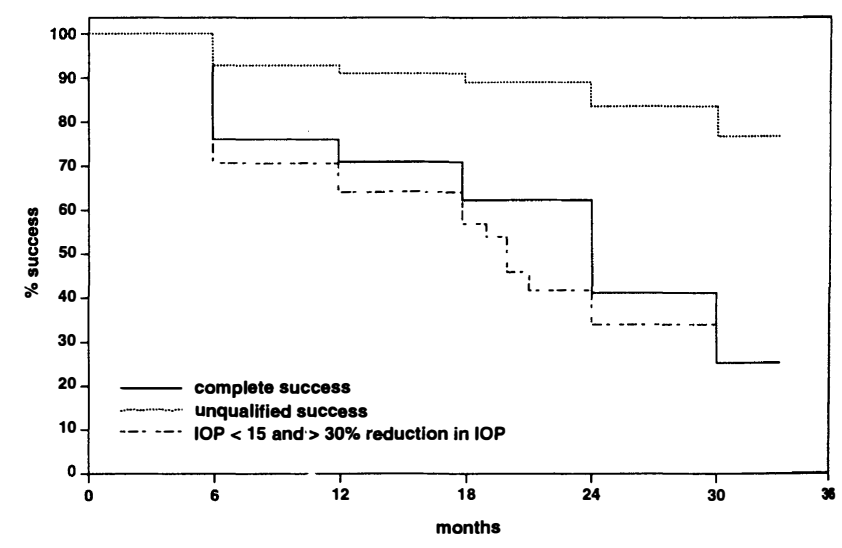

Fig. 2. Kaplan-Meier survival analysis of trabeculectomy with per-operative sponge 5-fluorouracil. 

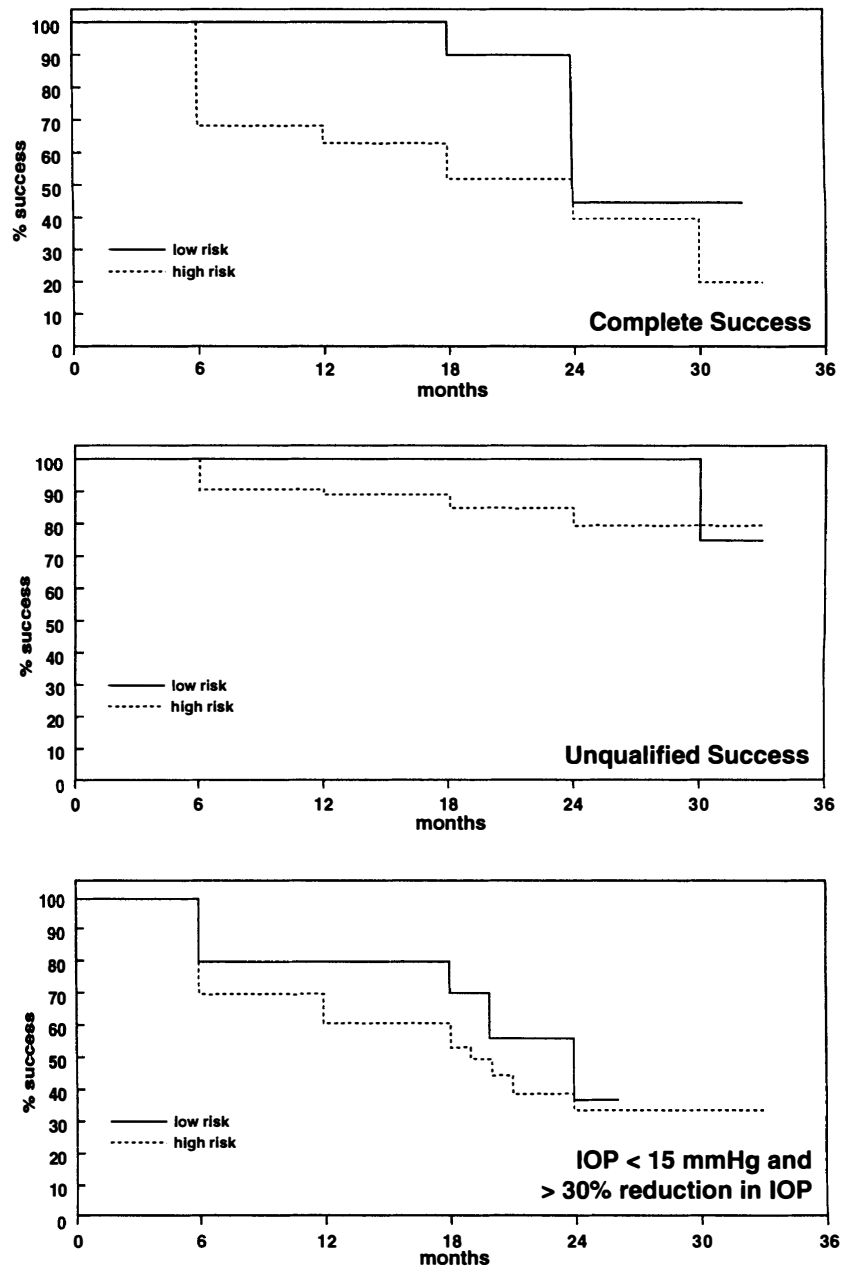

Fig. 3. A comparison of the Kaplan-Meier survival curves between the high-and low-risk groups according to the different success criteria.

Visual field tests were performed in 30 of 45 patients $(67 \%)$. Perimetry was not performed in those patients whose visual acuity was too poor for meaningful field assessment. The types of perimeter used were as follows: Medmont, 14 cases; Humphrey (24-2 program), 6; Goldmann, 5; Friedmann, 5. Only 2 patients showed evidence of deterioration in the visual fields. The first was a 72-year-old man with primary open angle glaucoma (POAG) who demonstrated progression of superior and inferior arcuate scotomas 2 years post-operatively in the presence of good IOP control. The IOP at 2 years was $8 \mathrm{mmHg}$ and did not rise above $14 \mathrm{mmHg}$ throughout followup. The second patient was a 78-year-old woman with POAG who also demonstrated progression of upper and lower arcuate scotomas at the 12 month follow-up visit in the presence of an IOP below $15 \mathrm{mmHg}$. One patient showed documented evidence of progression of glaucomatous disc damage following surgery. This was a 19-year-old man with severe uveitic glaucoma and poor IOP control whose optic disc cupping over a $2 \frac{1}{2}$ year period deteriorated from a cup-to-disc ratio of 0.9 to an end-stage cup in the presence of a reduction in visual acuity from $6 / 12$ to $6 / 60$.

Table III summarises the complications encountered. There were no serious bleb-related or corneal complications amongst those patients requiring postoperative subconjunctival injections of 5-FU. Hypotony maculopathy was seen in 2 eyes, 1 of which settled spontaneously 2 weeks post-operatively. The second case required four surgical procedures to revise the bleb, the last of which was combined with a phacoemulsification with foldable intraocular lens implant through a separate clear corneal incision. The IOP at the last follow-up was $11 \mathrm{mmHg}$ on no topical medication with a visual acuity of $6 / 6$. There was 1 case of leaking bleb 5 days post-operatively which settled spontaneously after 6 days, and 1 case of persistent corneal epithelial defect which lasted for 1 year. This, however, was in a patient who had had a previous corneal graft for Acanthamoeba keratitis.

Amongst the late complications there was 1 case of delayed epithelial defect occurring 3 months postoperatively which settled after 6 weeks. There were 4 cases of leaking bleb, 1 at 1 year which resolved spontaneously, another which required refashioning of the conjunctiva 9 months post-operatively and 2 which were described as transconjunctival pinpoint leaks which were observed. About half the blebs $(49 \%)$ were described as cystic, 1 of which was a giant bleb overhanging the cornea (initially a Tenon's cyst) which did not require surgical revision. There were no cases of bleb-related endophthalmitis. Retinal detachment occurred in 2 eyes: an aphakic eye in which there was vitreous loss at the time of trabeculectomy and a myopic pseudophakic eye.

Cataract occurred in 4 cases, 1 of which was progression of pre-existing lens opacities; 3 of these cases underwent successful phacoemulsification with lens implantation. At the last follow-up, visual acuity

Table III. Intraoperative, early and late post-operative complications

\begin{tabular}{|c|c|}
\hline $\begin{array}{l}\text { Intraoperative } \\
\text { Vitreous loss }\end{array}$ & $1(2 \%)$ \\
\hline $\begin{array}{l}\text { Early (within } 2 \text { months) } \\
\text { Hyphaema } \\
\text { Encysted bleb } \\
\text { Choroidal detachment } \\
\text { Subconjunctival 5-FU } \\
\text { Hypotony maculopathy } \\
\text { Anterior uveitis } \\
\text { Flat anterior chamber (re-formed) } \\
\text { Bleb leak } \\
\text { Epithelial defect } \\
\text { Revision of trabeculectomy }\end{array}$ & $\begin{array}{rc}11 & (24 \%) \\
9 & (20 \%) \\
6 & (13 \%) \\
6 & (13 \%) \\
2 & (4 \%) \\
2 & (4 \%) \\
2 & (4 \%) \\
1 & (2 \%) \\
1 & (2 \%) \\
1 & (2 \%)\end{array}$ \\
\hline $\begin{array}{l}\text { Late } \\
\text { Cystic bleb } \\
\text { Giant bleb } \\
\text { Leaking bleb } \\
\text { Cataract } \\
\text { Refashioning of bleb } \\
\text { Retinal detachment } \\
\text { Epithelial defect }\end{array}$ & $\begin{array}{rc}22 & (49 \%) \\
1 & (2 \%) \\
4 & (9 \%) \\
4 & (9 \%) \\
2 & (4 \%) \\
2 & (4 \%) \\
1 & (2 \%)\end{array}$ \\
\hline
\end{tabular}


was within 1 line or better than pre-operative levels in 41 of 45 eyes (Table I). Of the 4 cases with a deterioration in visual acuity, there were 2 retinal detachments (6/9 to CF, and CF to PL), 1 posterior subcapsular cataract $(6 / 9$ to $6 / 18)$ that has not yet required surgery and 1 case of chronic uveitis with progression of glaucoma (6/12 to $6 / 60)$.

\section{DISCUSSION}

Blumenkratz was the first to use 5-FU in ophthalmology in 1982 for the treatment of experimental vitreoretinopathy. It has since gained wide acceptance as a useful antiproliferative agent in glaucoma surgery. Initially applied as a series of post-operative injections, it was not until the early 1990s that the per-operative application of 5-FU on a sponge was first suggested. The rationale was that by applying the drug directly to the sclera, only the target tissues would be exposed to maximal drug concentration, and thereby the incidence of 5-FU related complications would be expected to be reduced.

The unqualified success rate (IOP $<21 \mathrm{mmHg}$ with or without medications) of $80 \%$ in this group of largely high-risk patients compares favourably with the pilot study of Lanigan et al. ${ }^{19}$ (91\% unqualified success rate) where the maximum follow-up was only 9 months. Traditionally the arbitrary figure of 20 or $21 \mathrm{mmHg}$ has been used as the target pressure by which success is defined, but it is now recognised that lower IOPs (i.e. in the low teens) are considered to be desirable for optic nerves already damaged by glaucoma. The third criterion for outcome, i.e. an IOP $<15 \mathrm{mmHg}$ and $>30 \%$ reduction, as used by Mora et al., ${ }^{22}$ therefore provides the most realistic assessment of the value of per-operative 5-FU in high-risk patients. Table II demonstrates that at last follow-up, this goal is being achieved in only $47 \%$ of eyes $(n=21)$, one third of which $(n=7)$ required topical medication. If those patients requiring topical medication are excluded, then by the strictest definition of outcome (IOP $<15 \mathrm{mmHg}$ and $>30 \%$ reduction, without medication) the success rate falls to $31 \%(n=14)$.

The Kaplan-Meier curve (Fig. 2) shows that at 33 months post-operatively, using the most lenient criterion, the success rate is maintained at $77 \%$. However, if the more stringent criteria are applied there is a steady drop-out as more eyes fail to survive, until at 33 months only $25 \%$ are maintaining an $\mathrm{IOP}<15 \mathrm{mmHg}$ and $>30 \%$ reduction. It would appear, therefore, that the longer the post-operative period, the greater the failure rate, and over the longer term the ability to maintain a low IOP amongst a high number of patients is disappointing. The Kaplan-Meier statistics do, however, become less reliable as the post-operative interval increases, due to the fact that the success rates are calculated from fewer patients and therefore any failures produce a much greater proportional loss of survival. It is interesting to note that there was no significant difference in the long-term survival between the lowrisk and high-risk groups, although the low-risk group tended to fare better within the first 12-18 months. It should also be noted that the number in the low-risk group was small $(n=10)$, making comparison less meaningful.

Comparison with the study of Mora et $a l^{22}$ is difficult because approximately half the patients in that study had no increased risk for surgical failure. If these 'low-risk' patients are excluded, they would still appear to have slightly more favourable results, with $90 \%$ achieving an IOP $<21 \mathrm{mmHg}$ (allowing medications) and $62 \%$ achieving an IOP $<15 \mathrm{mmHg}$ with $>30 \%$ drop in IOP (allowing medications). It should be noted, however, that the follow-up period in this study was shorter than in our study (mean 16 months, range 2-42) where the minimum follow-up was 12 months; the concentration of $5-\mathrm{FU}$ used was $50 \mathrm{mg} / \mathrm{ml}$ compared with $25 \mathrm{mg} / \mathrm{ml}$ in the current study; and $29 \%$ of their patients had a pre-operative IOP of less than $21 \mathrm{mmHg}$. Accurate comparison is also hampered by the variation in risk profile of the different patient groups. For example, all high-risk patients were included in the current 5-FU study whereas in the study by Mora et al. some of the very high-risk patients were assigned to MMC trabeculectomy and therefore not represented in their results.

By way of comparison with intraoperative sponge MMC for high-risk patients, there is a lack of published data examining the success in achieving IOPs in the low teens, even in the short term. Skuta et al. ${ }^{14}$ found that in 20 eyes, $60 \%$ achieved an IOP of $12 \mathrm{mmHg}$ or less at 6 months, and $74 \%$ were medication free. These figures are comparable with those of Mora et al. ${ }^{22}$ using sponge 5-FU (62\% IOP $<15 \mathrm{mmHg}$ with $>30 \%$ reduction, $70 \%$ medication free) and would appear to be superior to the results of this study $(47 \%$ IOP $<15 \mathrm{mmHg}$ and $>30 \%$ reduction, $49 \%$ medication free) bearing in mind the short length of follow-up. At the 6 month follow-up visit in this study our equivalent figures are $71 \%$ IOP $<15 \mathrm{mmHg}$ (and $>30 \%$ reduction) with $76 \%$ medication free.

Although the primary endpoint of the study was IOP control rather than preservation of visual function, visual acuity and visual field data were analysed, accepting the limitations of recording data in a retrospective study. Computerised automated perimetry has done much to improve the assessment of a patient's visual status, although a simple, accurate and economically viable method of both high specificity and sensitivity for early detection of significant change in an individual's visual field has 
yet to be developed. In view of these problems, control of IOP has traditionally been used as the main criterion for success. Measurement of IOP is easy, accurate, reproducible and objective, and provides data that are easily analysed statistically. The term 'success' is therefore synonymous with surgical success rather than disease control, although a lower IOP cut-off level is likely to bring pressure control in line with disease control.

The fact that $33 \%(n=15)$ of patients were unable to perform a useful field test reflects an advanced state of visual impairment. This high degree of preoperative damage reduces the ability to detect a treatment effect. Despite this, visual acuity was well maintained (within 1 Snellen line or better) in $91 \%$ $(n=41)$ of patients and only 2 of the 30 patients who performed perimetry demonstrated progression of arcuate scotomas at 12 and 24 months post-operatively, both of whom maintained IOPs at or below $15 \mathrm{mmHg}$. Clinical estimation of progression of glaucomatous optic disc cupping is even less reliable in a retrospective case note analysis when one is reliant on the subjective assessment of cup-to-disc ratios (CDR) and the variable artistic skills of a number of different doctors, rather than serial optic disc photographs. There was nevertheless documented progression of optic disc cupping (CDR 0.9 to $1.0)$ in only 1 case, this being in a 19 -year-old man with severe uveitic glaucoma and poorly controlled IOP whose visual acuity dropped from $6 / 12$ to $6 / 60$ over $2^{1 / 2}$ years of follow-up.

There was a low rate of corneal complications, with only 2 eyes $(4 \%)$ developing epithelial defects. Corneal epithelial cells are particularly susceptible to the effects of 5-FU, and the incidence of cornealrelated problems appears to be much greater with the use of subconjunctival injections, rates varying between $29 \%$ and $64 \%$ depending on the dose of 5-FU used. ${ }^{18,32}$ This could be attributable to the fact that 5-FU applied per-operatively remains relatively localised to the area of application and is then rapidly washed away during irrigation. Thorough irrigation following application of the sponge minimises the risk of 5-FU entering the anterior chamber when creating the ostium, thus avoiding toxicity to the corneal endothelium, ${ }^{33}$ the lens ${ }^{33}$ and the ciliary body. In contrast, following a subconjunctival injection, 5-FU can leach out of the puncture site into the pre-corneal tear film, thereby remaining in contact with the corneal epithelium for several hours.

Late bleb leaks were detected in 4 eyes $(9 \%)$, in addition to 1 case occurring within the first week. By taking care to avoid contact between the cut conjunctival wound edge and the sponge, and by meticulous suturing of the conjunctiva, the incidence of wound dehiscence and wound leaks in the early post-operative period can be minimised. Antimeta- bolite administration per se does not cause a wound leak in the early post-operative period, since the wound should be held watertight by the suture regardless of the degree of healing; however, it will unmask an inadequately closed wound. The incidence of bleb leak in this study was considerably lower than the $25-35 \%$ reported by other studies using post-operative injections. ${ }^{18,34}$ Ocular hypotony associated with maculopathy was seen in 2 patients $(4 \%)$ in the early post-operative period. In 1 case this persisted for many months and required several surgical revisions to the bleb before a successful outcome in terms of visual recovery (6/6) and IOP control $(11 \mathrm{mmHg})$ was achieved. Prata et al. ${ }^{35}$ found hypotonous maculopathy in $4.1 \%$ of all their MMCtreated eyes compared with an incidence of $1.3 \%$ in eyes treated with post-operative 5-FU. Long-term hypotony is a potentially serious complication $34,36,37$ and permanent visual impairment may result from chronic macular changes. Young myopic eyes appear to be most at risk, perhaps due to low scleral rigidity. ${ }^{37}$ Giant bleb, which overhangs the cornea, is another long-term bleb-related complication which often gives rise to a persistent foreign body sensation and ocular surface disturbance. The single case encountered in this series did not require surgical excision. ${ }^{36}$

Late bleb-related endophthalmitis is a potentially devastating complication which has been reported following the use of 5-FU given post-operatively, at rates varying between $1.9 \%$ and $9.4 \% .^{7,34,36,38}$ These are high rates for such a severe complication and it is interesting to note the higher figure of $9.4 \%$ resulted from inferiorly located blebs. ${ }^{38}$ It is encouraging, therefore, to report that there were no cases of bleb infection or endophthalmitis from this series, although nearly $50 \%$ of the blebs were described as cystic. Whilst it has been shown that lower IOPs are achieved with the use of adjunctive 5-FU in patients undergoing primary filtration surgery, ${ }^{34,39}$ the presence of these large thin-walled cystic blebs undoubtedly represents a potential route of entry for bacterial pathogens and thus infection remains a risk.

A relatively high incidence of bleb-related sequelae ( 8 cases, 18\%) was noted in this study. These comprised leaking bleb in 5 cases, hypotony maculopathy in 2 cases and giant bleb in 1 case. This has been the experience of other studies after filtering operations with post-operative 5 -FU. ${ }^{6-9,34,36,38,39}$ The increased incidence of bleb-related sequelae suggests a relative weakening of the bleb wall, most likely due to the toxic effect of 5-FU on the existing activated fibroblasts which has been reported experimentally ${ }^{2-4}$ as well as in human eyes after trabeculectomy. ${ }^{40}$

In an era of peri-operative use of antimetabolites such as 5-FU and MMC, the possibility of late 
complications should always be considered. Due to its profound and permanent toxic effects on activated fibroblasts, ${ }^{2,15}$ MMC produces blebs which tend to be thinner and more avascular than those seen with 5-FU. A recent paper describing trabeculectomy blebs after the use of $\mathrm{MMC}^{41}$ showed that the conjunctiva had an irregular epithelium with a largely acellular and avascular substantia propria. Breaks in the basement membrane of the basal layer of the conjunctiva were also detected, which could allow slow transudation of aqueous through the bleb with the attendant risks of transient or chronic leaks, late infections or ruptures. In addition scleral necrosis, which has previously been recognised to occur following pterygium excision with adjunctive topical MMC, ${ }^{42,43}$ has now recently been reported with the use of per-operative sponge MMC during trabeculectomy. ${ }^{10}$

Antimetabolites are certainly indicated in eyes with a high risk for post-operative scarring, and MMC in particular may have a role in cases of uveitis and neovascularisation, where a more prolonged inhibition of local fibroblast proliferation is required. This is supported by the results of a recent study in which the outcome of 5-FU filtering surgery for neovascular glaucoma (using post-operative injections) was poor, particularly in those under 50 years of age. ${ }^{44}$ The results of this study confirm that the technique of applying 5-FU per-operatively to the sclera during trabeculectomy is a useful adjunctive treatment in low- to moderate-risk patients, at least in the short to medium term. It shares the same benefits of a single intraoperative exposure to MMC (i.e. removal of the need for post-operative injections and reduced incidence of corneal complications); however, due to its less prolonged and reversible effects on subconjunctival and scleral fibroblasts, it may be a safer treatment option. Nevertheless, 5-FU should be used with caution and its use in initial surgery in uncomplicated cases, as has been advocated by some, ${ }^{34,39}$ under the current regimes and dosages, should be carefully considered. It is likely, however, that in future the doses of single applications of 5-FU could be varied in much the same way as those of MMC. ${ }^{10-14}$ A concentration of $50 \mathrm{mg} / \mathrm{ml}$ was initially used because of the known efficacy of this dose in post-operative application, but it is likely that the release of 5-FU from the sponge is variable, as has been shown with MMC. ${ }^{45}$ Indeed by altering concentration, sponge size or exposure time, unwanted side-effects could be minimised whilst preserving the IOP-lowering effect.

We are grateful for the contribution of Dr Bill Adams, Department of Medical Statistics, University of Edinburgh Medical School.

Key words: Trabeculectomy, 5-Fluorouracil, Per-operative.

\section{REFERENCES}

1. Hitchings RA, Grierson I. Clinicopathological correlations in eyes with failed fistulising surgery. Trans Ophthalmol Soc UK 1983;103:84-8.

2. Khaw PT, Sherwood MB, MacKay SLD, Rossi MK, Schultz GS. Five minute treatments with fluorouracil, floxuridine and mitomycin have longterm effects on human Tenon's capsule fibroblasts. Arch Ophthalmol 1992;110:1150-4.

3. Khaw PT, Ward S, Porter A, Grierson I, Hitchings RA, Rice NSC. The longterm effects of 5-fluorouracil and sodium butyrate on human Tenon's fibroblasts. Invest Ophthalmol Vis Sci 1992;33:2043-52.

4. Yamamoto T, Varani J, Soong HK, Lichter PR. Effects of 5-fluorouracil and mitomycin $\mathrm{C}$ on cultured rabbit subconjunctival fibroblasts. Ophthalmology 1990;97: 1204-10.

5. Salmon SE, Scatorelli AC. Cancer chemotherapy. In: Katzung BG, editor. Basic and clinical pharmacology. California: Lange Medical Publications, 1987:667-8.

6. The Fluorouracil Filtering Surgery Study Group. Fiveyear follow-up of the fluorouracil filtering surgery study. Am J Ophthalmol 1996;121:349-66.

7. Rockwood EJ, Parrish RK, Heuer DK, et al. Glaucoma filtering surgery with 5-fluorouracil. Ophthalmology 1987;94:1071.

8. Ruderman JM, Welch PB, Smith FM, Shoch DE. A randomised study of 5-fluorouracil and filtration surgery. Am J Ophthalmol 1987;104:218.

9. Nakano Y, Araie M, Sirato S. Effect of post-operative subconjunctival 5-fluorouracil injections on the surgical outcome of trabeculectomy in the Japanese. Graefes Arch Clin Exp Ophthalmol 1989;227:569.

10. Singh J, O'Brien C, Chawla HB. Success rate and complications of intraoperative $0.2 \mathrm{mg} / \mathrm{ml}$ mitomycin $\mathrm{C}$ in trabeculectomy surgery. Eye 1995;9:460-6.

11. Chen CW, Huang HT, Bair JS, Lee CC. Trabeculectomy with simultaneous application of mitomycin $\mathrm{C}$ in refractory glaucoma. J Ocul Pharmacol 1990;6:175-82.

12. Palmer SS. Mitomycin as adjunctive chemotherapy with trabeculectomy. Ophthalmology 1991;98:317-21.

13. Kitazawa Y, Suemori-Matsushita H, Yamamoto T, Kawase K. Low dose and high dose mitomycin trabeculectomy as an initial surgery in primary open angle glaucoma. Ophthalmology 1993;100:1624-8.

14. Skuta GL, Beeson CC, Higginbotham EJ, et al. Intraoperative mitomycin versus postoperative 5-fluorouracil in high risk glaucoma filtering surgery. Ophthalmology 1992;99:438-44.

15. Khaw PT, Doyle JW, Sherwood MB, Grierson I, Schultz GS, McGorray S. Prolonged localised tissue effects from 5 minute exposures to 5-fluorouracil and mitomycin C. Arch Ophthalmol 1993;111:263-7.

16. Jampel HD, Pasquale LR, Dibernardo C. Hypotony maculopathy following trabeculectomy with mitomycin C. Arch Ophthalmol 1992;110:1049-50.

17. Higginbotham EJ, Stevens RK, Musch DC, Karp KO, Lichter PR, Bergstrom TJ, Skuta GL. Bleb-related endophthalmitis after trabeculectomy with mitomycin C. Ophthalmology 1996;103:650-6.

18. The Fluorouracil Filtering Surgery Study Group. Fluorouracil filtering surgery study: one year followup. Am J Ophthalmol 1989;108:625-35.

19. Lanigan L, Sturmer J, Baez KA, Hitchings RA, Khaw PT. Single intraoperative applications of 5-fluorouracil during filtration surgery: early results. $\mathrm{Br} \mathrm{J}$ Ophthalmol 1994;78:33-7. 
20. Egbert PR, Williams AS. Singh K, Dadzie P, Egbert TB. A prospective trial of intraoperative fluorouracil during trabeculectomy in a black population. Am J Ophthalmol 1993;116:612-6.

21. Dietze PJ, Feldman RM, Gross RL. Intraoperative application of 5-fluorouracil during trabeculectomy. Ophthalmic Surg 1992;23:662-5.

22. Mora JS, Nguyen N, Iwach AG, et al. Trabeculectomy with intraoperative sponge 5-fluorouracil. Ophthalmology 1996;103:963-70.

23. Singh J, Bell RWD, Adams A. O'Brien C. Enhancement of post-trabeculectomy bleb formation by laser suture lysis. Br J Ophthalmol 1996;80:624-7.

24. Heuer DK, Parrish RK II, Gressel MG, Anderson DR, Hodapp E, Palmberg PF. Trabeculectomy in aphakic eyes. Ophthalmology 1984;91:1045-51.

25. Stewart RH, Kimbrough RL, Bach H, Allbright M. Trabeculectomy and modifications of trabeculectomy. Ophthalmic Surg 1979;10:76-80.

26. Heuer DK, Parrish RK II, Gressel MG, et al. 5-Fluorouracil and glaucoma filtering surgery. III. Intermediate follow-up of a pilot study. Ophthalmology 1986;93:1537-46.

27. Lavin MJ, Wormald RPL, Migdal CS, Hitchings RA. The influence of prior therapy on the success of trabeculectomy. Arch Ophthalmol 1990;108:1543-8.

28. Broadway DC, Grierson I, O'Brien C, Hitchings RA. Adverse effects of topical antiglaucoma medication. I. The conjunctival cell profile. Arch Ophthalmol 1994;112:1437-45.

29. Broadway DC, Grierson I, O'Brien C, Hitchings RA. Adverse effects of topical antiglaucoma medication. II. The outcome of filtration surgery. Arch Ophthalmol 1994;112:1446-54

30. Miller RD, Barber JC. Trabeculectomy in black patients. Ophthalmic Surg 1981;12:46-50.

31. Sturmer J, Broadway DC, Hitchings RA. Young patient trabeculectomy: assessment of risk factors for failure. Ophthalmology 1993;100:928-39.

32. Weinreb RN. Adjusting the dose of 5-fluorouracil after filtration surgery to minimise side effects. Ophthalmology 1987;94:564-70.

33. Freyer EB, Chaturvedi N, Zurakowski D. Effect of mitomycin $\mathrm{C}$ and fluorouracil-supplemented trabeculectomies on the anterior segment. Arch Ophthalmol 1995;113:578-80.
34. Whiteside-Michael J, Liebmann JM, Ritch R. Initial 5-fluorouracil trabeculectomy in young patients. Ophthalmology 1992;99:7-13.

35. Prata JA, Seah SKL, Minckler DS, et al. Postoperative complications and short-term outcome of 5-fluorouracil or mitomycin C trabeculectomy. J Glaucoma 1995; $4: 25-31$.

36. Ticho U, Ophir A. Late complications after glaucoma filtering surgery with adjunctive 5-fluorouracil. Am J Ophthalmol 1993;115:506-10.

37. Stamper RL, McMenemy MG, Lieberman MF. Hypotonous maculopathy after trabeculectomy with subconjunctival 5-fluorouracil. Am J Ophthalmol 1992; 114:544-53.

38. Wolner B, Liebmann JM, Sassani JW, Ritch R, Speaker M, Marmor M. Late bleb-related endophthalmitis after trabeculectomy with adjunctive 5-fluorouracil. Ophthalmology 1991;98:1053-60.

39. Liebmann JM, Ritch R, Marmor M, Nunez J, Warner B. Initial 5-fluorouracil trabeculectomy in uncomplicated glaucoma. Ophthalmology 1991;98:1036-41.

40. Ophir A, Ticho U. Toxic effects of 5-fluorouracil on fibroblasts following trabeculectomy. Ophthalmic Res 1992;24:298.

41. Mietz H, Brunner R, Addicks K, Krieglstein GK. Histopathology of an avascular filtering bleb after trabeculectomy with mitomycin C. J Glaucoma 1993; 2:266-70.

42. Rubinfield RS, Pfister RR, Stein RM, et al. Serious complications of topical mitomycin $\mathrm{C}$ after pterygium surgery. Ophthalmology 1992;99:1647-54.

43. Fujitani A, Hayasaka S, Shibuya Y, Noda S. Corneoscleral ulceration and corneal perforation after pterygium excision and topical mitomycin C. therapy. Ophthalmologica 1993;207:162-4.

44. Tsai JC, Feuer WJ, Parrish RK II, Grajewski AL. 5-Fluorouracil filtering surgery and neovascular glaucoma: longterm follow-up of the original pilot study. Ophthalmology 1995;102:887-92.

45. Yamamoto $\mathrm{T}$, Kitazawa Y. Residual mitomycin $\mathrm{C}$ dosage in surgical sponges removed at the time of trabeculectomy. Am J Ophthalmol 1994;117:672-3. 